\title{
Fixity and Flow in Garth Nix's Sabriel
}

\author{
Alice Mills
}

$\mathrm{G}$ arth Nix is an Australian writer of fantasy for children and young adults. His fantasy fiction spans a wide range of themes, from the uncanny 1991 witch-doll tale, The Ragwitch, to the 1997 urban dystopia, Shade's Children; from the (as yet incomplete) hero-quest heptalogy, The Seventh Tower, to the series of (so far) heroine-centred quest stories about necromancy of which two volumes have been published, the 1995 Sabriel and its 2001 sequel, Lirael. Of these novels, it was Sabriel that brought Nix into prominence as a fantasy writer when, in 1995, it won the 1995 Aurealis award and was chosen as an Australian Book Council Notable Book, and in 1997 it was chosen as an ALA Honor book. Little critical attention, however, has so far accompanied the recognition by the award judges of his quality as a novelist.

Sabriel's strength as a fantasy novel lies in its sabotage of a typical quest story pattern, that of the distinction between the world of the dead and the world of the living. Nix's choice of a female quest hero might suggest that he is subverting the gender pattern of hero quests as depicted (and deplored) in Hourihan's Deconstructing the Hero; but Sabriel herself is defined as her father's daughter and successor, destined to take his place as Abhorsen (necromancer on the side of good) and maintain the proper boundaries between life and death. The typical roles of man and woman in fairy tale quest are reversed when Sabriel brings a prince back to life out of suspended animation with a kiss, but in the end her powers prove inadequate to defeat the returning dead and it is her father who rescues her and saves the world. Nix's novel thus reinforces 'the concept of women's inherently ancillary role' (Hourihan 1997, p. 174).

Sabriel is not, then, subversive in Hourihan's terms, nor is its disturbing power susceptible to a Todorov-style analysis. Nix's fantasy world exemplifies the 'marvellous' in Todorov's tripartite schema, the world that is indubitably not our ordinary waking reality. Though the inhabitants of the neighbouring 'steam-age civilisation' country (http://www.sf.org.au/aurealis/aal995.html) doubt or disbelieve in necromantic magic, the book's reader is left in no doubt that necromancy and wild magic are real. Nix leaves the reader no room for the hesitation that is Todorov's mark of true 'fantasy', and his work is not centrally concerned with the intrusion of magic into something like our ordinary reality: thus according to Todorov's schema, the uncanny cannot occur here. It is my contention that Todorov's tripartite schema is inadequate to fantasy fiction like Sabriel. If the 'marvellous' world of magic is taken on its own terms as ordinary reality for the characters of that world, then aspects of Todorov's 'uncanny' can be detected in peculiarities within that fictional reality. A Freudian reading of the 'uncanny' as the return of the repressed into the ordinary reality of Nix's fictional world raises none of the difficulties of Todorov's mutually exclusive 'uncanny' and 'marvellous', and for the remainder of my paper it is the Freudian, psychoanalytic uncanny that I use as my theoretical context.

Sabriel is an Abhorsen, and though her title suggests 'abhorrence', her hereditary duty is to put an end to the abhorrent, malevolent, murderous intrusions into the world of the living by the evil dead and their supernatural allies, creatures of Free Magic like the demonic Mordicant. Sabriel's quest is to find the trapped body, then the trapped spirit, of her father (the previous Abhorsen), and bring him back to life to deal with enemies too mighty for her, the Mordicant and wicked prince Kerrigor. On the side of good are Sabriel and her father, all the Charter mages who honour the Charter magic that regulates the kingdom, and some supernatural beings whose origins and precise nature remain mysterious in this novel. The book's overall scenario, though, is a familiar one in horror literature: that of a good demon-hunter seeking to restore a proper boundary between the living and the dead.

It comes as no surprise to learn that running water is the living world's strongest deterrent to the revenant dead, along with the lesser protections of rowan and silver, and the cutting power of swords. Equally unsurprising, though memorably imagined in terms of sight, sound and touch, is the river of death into which the Abhorsen repeatedly walks to retrieve the recently dead or those trapped by magic. The image of a river of death, explored by a hero, goes back in Western literature via Dante's vision of the rivers of hell to the ancient Greek Styx and Acheron with 
the ferryman of the dead, and Apuleius' story of Psyche whose ordeals, in her descent to the underworld, include denying help to the demanding, pleading people in the waters of death across which she is being transported. Before the Greeks, the image of a river of death goes back to the Egyptian night-sea voyage of the sun-god, conveying the souls of the virtuous dead to a blessed afterlife while the unworthy dead are tormented and eaten along the way.

Such journeys along the river of death are only one way trips for the dead, and some dead souls remain stuck in its waters: Dante interviews stuck souls in torment but rescues none of them, and Psyche's task is to find the inner strength not to be distracted from her quest, however desperate or poignant the calls of the dead upon her attention. In contrast, Nix's Abhorsens have the power to restore the recently dead to life, and part of their duty is to rescue those magically trapped in the river before their proper time to die. With these exceptions, $\mathrm{Nix}$ follows the ancient image of the soul's watery journey, in so far as the river of death is the right channel along which all the dead should pass. In this novel, death should be a one way trip. Sabriel's death-river flows down nine stretches of water, separated by nine waterfall Gates, and the dead's final place lies beyond the knowledge of the living, past the Ninth Gate, where magic can no longer affect them. This river is no place of hellish torment but a natural means of transition, except for those evil dead whose will is set on survival and return to the living world, and the other dead whom they enslave. It is the Abhorsen's duty to ensure that both good and bad dead travel past the final waterfall.

Garth Nix thus achieves a powerfully uncanny effect when the imagery of the river of death plays against the imagery of flowing water as a defence against the evil dead. His evocation of the evil dead themselves, and of their supernatural allies, tends to be cursory-fiery eyes, flesh disintegrating from bone-but the book's true horror lies in the close similarity between water that provides safety and life, and water from which issues dread. The running water which provides a strong boundary in the living world, is not a boundary but a channel for the evil dead in the world of the dead. These beings, and their Free Magic allies, seem as adept as the Abhorsen at withstanding the current of the river's first stretch, avoiding the hidden holes of its second stretch, running fast enough to avoid the third stretch's waves ${ }^{2}$ and climbing the waterfalls. The effect of this contradiction between flowing water as a barrier and flowing water as a means to cross the barrier, is uncanny: what seemed familiar, even stereotypical of the genre, suddenly sabotages itself, opening the way between life and death.

Nix sets up a momentary paradox when Sabriel cleanses an island of a Mordaut. This supernatural creature of Free Magic possesses one of the fisherfolk who has sought refuge across the river when the dead attack their village. The island offers sanctuary because running water, especially the chaotic sea, is a boundary that the dead cannot cross. Yet when Sabriel detects the Mordaut and uses the power of her bells to ring it back down the river of death, 'it slid back down again-and vanished. Back into Death, to bob and spin in the current, howling and screaming with whatever voice it had there, all the way through to the Final Gate' (Nix 1995, p.184). In this episode, water as barrier and water as a channel through which the dead travel, are almost simultaneously evoked. Such juxtaposition raises the question why water successfully bars the dead, in the world of the living, if the dead can travel up the river of death by will-power and are forced to travel down its current by Sabriel's bells.

A more extended example of Nix's paradox occurs in the waters surrounding the Abhorsen's house that Sabriel flees to, unfamiliar to her because she has spent most of her life away at boarding school. She is fleeing from the Mordicant after vainly attempting to send it back to the river of death. Her house is protected from the Mordicant and its host of living and dead slaves, because it is built on an island at the top of a waterfall, with fast-flowing water on all sides. Sabriel learns that she can protect herself further by summoning a flood, when the Mordicant threatens to bridge the top of the falls with boxes of gravedirt. Such protections make it risky for Sabriel to reach her house. She must jump from one slippery stone to another, in danger of being swept to her death down the waterfall. The geography of this island and its waterfall is very like that of the river of death. Sabriel's unsteady footing on the stepping stones is like her difficulties in 
standing fast in the current of the death-river's first stretch, while the mighty flood-wave that washes away the dead and their grave-dirt bridge, recalls the third section of the river of death, with its overwhelming waves. Thus Sabriel's protective flood is a manifestation in life of death's wide waters. While she finds herself at risk of being swept down the waterfall to her death, as she crosses to the island, all those who threaten her have either climbed up waterfalls in death or are under the control of a revenant. In this episode, then, flow as boundary becomes flow as channel, and Nix's uncanny effect is gained by putting both sets of implication into play at once.

A third example of Nix's uncanny writing occurs when Sabriel's Paperwing aircraft plunges into a sinkhole that leads to another sinkhole, a royal burial ground. Before the royal house (apparently) died out, royal rulers were buried here in ritual longships, 'their black sails set to catch a non-existent wind, oars out to battle an imaginary tide' (p.135). Such phrases evoke a sense of heroic struggle, but sit oddly with the book's full account of what happens after death, when the spirits of the good travel (if not interfered with) down all nine stretches of the river to a blessed afterlife beyond the Ninth Gate. Their journeys are effortless, yielding to the flow of death's river, and are quite unlike the way these longships seem poised for battle, ready to travel effortfully against the current, exactly as the book's evil dead use their willpower to battle their way up against the current and out again into life.

One of these ships has an unusually lifelike figurehead, which turns out to be a prince of the royal blood, suspended in body in the form of a wooden carving, and in spirit in the river of death. Sabriel ventures into the river of death and battles its tlow in order to drag his spirit back to life. Sabriel's struggle to retrieve the prince has the opposite aim from the royal burials (designed to ensure that the spirits of the dead cannot be drawn back to life by magic), despite their common imagery of strenuous movement against a flow. The sinkholes themselves, the royal buriai place and the treacherous opening in the earth into which the Paperwing falls, resemble the treacherous holes in the river of death's second reach. Falling into the sinkhole threatens Sabriel with several kinds of death. A sinkhole is not an innocent term in this watery novel.

Another term that is far from simple in its connotations is the 'spring' that rises up just below the longship where the prince has waited 200 years to be rescued. As a spring of fresh water it offers life to Sabriel, when she seems to be trapped in the interlinked sinkholes deep in the earth. The 'spring' also connotes the season of spring, an appropriate allusion here as the wooden prince gains new life, and he and Sabriel soon discover their love for one another. Both the season of spring and the prince's resurrection have overtones of Christ's resurrection from the dead at Easter, though prince Touchstone does not prove to be the saviour of this world. Rather, it is Sabriel who later dies and is resurrected as the world's saviour, with her sword casting the shadow of a cross on her temporarily dead body. The associations of spring with new life, resurrection from the dead and life-giving water, are not, however, altogether in accord with the details of Sabriel's visit to the river of death from the sinkhole to fetch back the prince's spirit. Springs of water 'spring up' from the ground, but Sabriel's efforts here are a matter not of leaping but of first dragging, then struggling to burst through, then collapsing. To win the prince's life back, she must work against the flow of the river of death. rather than following the leaping upsurge of a watery spring.

Another of the novel's watery peculiarities is the ice that freezes around the Abhorsen's body when he or she ventures into the river of death, leaving the body and travelling in spirit only. When Sabriel's father is released from weeks of bodily confinement in water, and of spirit entrapment in one of death's waterfalls, the layer of ice around his middle is thick enough to break apart into "several small tloes" as he revives. Even when the Abhorsen's visit to the river of death is short, and even when the Abhorsen's body is on dry land, frost and icicles are produced. Such images suggest both the chill of death and the stilling of life's flow in the body, blood and breath; but in a novel where death itself is represented as a flowing river, freezing seems an incongruous detail in the Abhorsen's visit to that river. The evil characters who emerge from the river, burn rather than freeze, and 
Sabriel cremates some of the bodies of those newly dead in order to ensure their safe and immediate passage beyond the Ninth Gate. It is only the Abhorsens, then, whose bodies generate frost and ice as their spirits traverse the river of death.

It is odd, too, that the Abhorsens' greatest enemy, wicked prince Kerrigor, does not generate frost and icicles when he is driven back into the river in spirit form. When his body is under attack in the world of the living, he produces not extreme cold but scalding hot steam. For 200 years he has hidden his original body, using temporary forms whenever he manages to wade out of the river of death, but when he is forced to reassume this first body, it proves to have 'eyes of fire' and 'his words came bubbling out like lava' (p.315), again generating heat rather than cold. Whether moving in and out of the river of death, or in and out of bodies, Kerrigor is associated with violent hot flows-steam, smoke, flame, lava. The phenomenon of freezing on entering the river of death, as living body separates from living spirit, seems unique to the Abhorsens.

The spirits of the dead are always in motion, or struggling to move, either towards or away from the Ninth Gate. Similarly, Sabriel and her father are always in motion when they function as Abhorsen, searching in the waters of death, retrieving spirits or forcing them downwards. Death in this novel is an extremely active form of being, and frozen water seems a strange choice on Nix's part as a physical manifestation of the spirit's entry into death's watery flow. The effect is uncanny. Frost and ice, traditionally associated with the chill of death, are here manifested by characters who have power over death. The chilling of a body in death is evoked, yet its implications are reversed, for frost around an Abhorsen body indicates that both body and spirit live. Similarly, the title 'Abhorsen' suggests 'abhorrence', but is given to characters who put an end to what is abhorrent. Like the play on 'floe' and 'flow', frost, ice and the Abhorsen title fit Freud's category of the uncanny: 'heimlich is a word the meaning of which develops in the direction of ambivalence, until it finally coincides with its opposite, unheimlich' (Freud 1956, p.226). It is just such a disconcerting interplay between opposing meanings that constitutes Nix's uncanny.
The manifestation of ice marks the Abhorsen's role as one of the land's Great Charters. There are five of these, including the mysterious Clayr who can magically convert water to ice, then use the frozen sheet as a window into far places and the future. The greater Charter Stones and the Wall are also Charters, and like the frozen-yet-moving Abhorsen, the Wall is both solid and endlessly moving with marks of power:

the very stones crawled with Charter marks-
marks in constant motion, twisting and turning.
sliding and rearranging themselves under a skin
of stone ( $\mathrm{p} .21)$.

The Abhorsen's sword of office bears words that similarly move. Perhaps all the Charter stones were also once simultaneously solid and in motion, but Kerrigor and his allies have progressively defiled and broken them, using the blood of royalty as another Charter, or for the lesser stones the blood of a Charter mage. The royal family seems to have no intrinsic ability to be at once magically in motion and frozen stiff. (When Kerrigor's brother Touchstone was turned to wood, it was through the Abhorsen's use of magic, to preserve him until Kerrigor should be defeated and the royal line could be restored.) Perhaps it is because the royal family has no power to freeze and move at the same time that they prove the most corruptible of the five Charters.

In this reading, the Abhorsens' frost and ice demonstrate their loyalty to the Charter, standing fast, uncorrupted, while Kerrigor's flames and his spilling of royal blood are fluid embodiments of his refusal to hold to the Charter that should bind the land. From this perspective, Nix's uncanny imagery of flowing water as both protection and a means for the dead to return, gains further subtleties of meaning. Running water functions as a protection for the living against the evil dead, but only for those who can stand fast in it, as the Abhorsen house stands fast against the flood. For the good dead, the equivalent is that state of being beyond the Ninth Gate where they can exist freely, for no magic can force them to move from there. It is only the good characters who want to travel the length of death's river in the instant of death, to reach that mysterious zone where they can stand fast, incorrupt, while the evil dead do all in their power to move back upstream. 
This association between standing fast and the Charter that binds the land in safety is exemplified in the good characters' stumbles as well as in their successes. When Sabriel's father is trapped in death, he sends a messenger to his daughter along the river of death. The creature stumbles and is washed away, its unsteadiness symptomatic of the Abhorsen's defeat. Sabriel, hard pressed by the Mordicant, finds it difficult to keep her balance on the stepping stones that lead across the top of the waterfall to her house. When Kerrigor attacks his brother Touchstone, the good prince is not injured but knocked off his feet. In order for the Charter to be maintained, the novel's embodiments of the Charter need both fixity and flow. Their weakness is revealed in undue yielding to flow, as they waver, collapse and are in danger of being swept down waterfalls. As a royal prince, Kerrigor is one of the Great Charters, and his corruption is made manifest in violent flows of steam and flame, and metaphorical bubblings of lava. For the Charter Stones, defilement is indicated both by their solid form's cracking and breaking, and by the undue fixity of what remains. Even a broken Charter Stone continues to bear Charter marks, but they no longer move:

There were Charter marks on this stone, but they were still, as frozen as the snow. Dead marks, nothing more than meaningless inscriptions, carved into a sculptured stone (p.51).

Here frost and stillness carry only their traditional associations with death, rather than indicating the uncorrupted Charter power at work. The effect is sinister but not uncanny.

The human body's yielding to undue flow manifests differently in Nix's final watery setting, the huge underground reservoir near the royal palace which houses the Great Charter Stones. Here, 200 years ago, Kerrigor murdered his mother the queen and her daughters, and used their blood to defile and break three of the Stones. Now Sabriel and her prince experience the water as polluted. It no longer of fers any protection against the returning dead. Instead, the bodies of the living turn against themselves, with symptoms that internalise the water's contamination: 'sweat broke out in lines on [the prince's] forehead, mirroring the ripples that spread from his entry' (p.223).

Similarly, Sabriel reacts to the water's touch 'like the sudden onset of gastric flu, bringing up stomach cramps, sudden sweat, and dizziness'. Such flow in a body out of control parallels the movement of the dead who fight their way-the wrong way-up and out of the river of death. In this episode, it is the bodies of the good characters that enact the passage of the dead through such orifices as sweat pores and mouths. Sabriel's 'wave of nausea' recalls the overwhelming waves of the river of death's third stretch. The prince has difficulty feeling his feet in the reservoir's waters, like Sabriel when she stands in death's chilly current. Neither of them can stand fast in this water. Sabriel half-collapses, and the good prince falls. Such uncontrolled movements are, as usual in this book, the human equivalents of the broken Charter Stones' inability to flow with words of power.

The world of Sabriel is morally simple. Characters are almost always either simply good or utterly evil, wearing intact Charter marks of baptism or else demonically aflame. In contrast, the novel's imagery is not reducible to simple binary opposites. Nix's abundant imagery of flow and freezing, extreme heat and cold, does not readily translate into straightforward categories of good and evil. Even the non-human helpers of the good characters inhabit an uncanny world where nothing is simple and where categories compete.

Sabriel and her father, as Abhorsens, have two principal helpers, a set of seven bells and Mogget the 'cat'. The Abhorsen's seven bells are powerful tools that can compel the dead, but several of them are said to carry a threat to their user. When the sad bell, Astarael, is rung, its power always sends the ringer to death along with all who hear. Kibeth is a bell that sometimes turns on its ringer:

\section{A bell of several sounds, a difficult and contrary bell. It could give freedom of movement to one of the Dead, or walk them through the next gate. Many a necromancer had stumbled with Kibeth and walked where they would not. (p.54)}

Belgaer is a 'tricksome bell, that sought to ring of its own accord'. Such phrasing suggests that the bells are not 
simply tools of the necromancer's trade but sentient beings in their own right, not necessarily inclined to help the Abhorsen. As such, they are uncanny in Jentsch's sense: "doubts whether an apparently animate being is really alive; or conversely, whether a lifeless object might not be in fact animate' (see Freud 1956, p.226).

There is a further puzzle about these bells' operation. They are heard by the Abhorsen who rings them, as well as by the dead who fall under their power, but Nix nowhere accounts for the Abhorsen's general immunity to their sound waves. Such immunity is of course necessary for the Abhorsen to function without immediately dying, but it also adds to the uncanny possibility that the bells may possess life and agency-yet not in a predictable manner. If the bells were totally under the necromancer's control, or totally beyond it, their workings would not be uncanny. A similar problem is posed by the bell on Mogget's collar, a miniature Saranath, whose full-scale version is rung by Sabriel to complete Mogget's transformation from Free Magic creature to helper. The miniature Saranath also peals, and it is not at all clear why Mogget as an operator of this bell does not have the same effect on Sabriel as she does on him.

Mogget, the talking 'cat', is a thoroughly equivocal helper. He is said to be a creature of Free Magic, or the Wallmaker's ancient construct from Wall and Charter Stone leftovers, or even, perhaps, the Wallmaker's child. As the Wallmaker's creation, he might be expected to help Sabriel unreservedly, but once released from the collar and bell that confine him in the form of a white cat, Mogget attacks her. He now takes the shifting form of a whirling column of white energy, all flow without fixity, and demands a blood-price. Sabriel has done him no wrong, and so his revenge must be for some long-ago injury received from an Abhorsen, presumably enslavement. As a whirling pillar of energy, he is aligned with Kerrigor's steam and smoke; and in the book's last pages, Kerrigor is also transformed first to a black pillar of swirl and then to a black cat.

Yet when Mogget attacks Sabriel, he does so very slowly, pausing as though to give her time to remember the ring that he has coughed up and told her to wear. This ring, thrown over his head, diminishes him again to the more homely figure of a white cat with collar and bell-a miniature version of the Abhorsen bell, Saraneth, that subdues its hearer's will. It remains unclear in this book whether Mogget is a helper playing at being the Abhorsen's mortal enemy, or a mortal enemy half-complicit with his captor. The two moments when Sabriel's father confronts the forces of death, with an uncollared Mogget at his side and not attacking him, suggest that he is indeed a true helper, but on this reading his reasons for attacking Sabriel are obscure.

At the novel's end Mogget is freed once more and again threatens to kill Sabriel, but he then turns on Kerrigor who is by now also a whirling pillar. Ostensibly, Mogget fights Kerrigor for the privilege of killing Sabriel; perhaps, however, he is trying to help her by becoming absorbed into Kerrigor's black pillar. Mogget seems to Sabriel to have been conquered and eaten, but a gleam of white shows in Kerrigor's blackness and gives her the idea of throwing her ring over Kerrigor. The swirl of energy is constricted to become two cats, black Kerrigor and white Mogget, each vomiting up a ring for Sabriel to control them if ever they are released again. Kerrigor's blackness equates with pure evil, but it remains doubtful whether Mogget is purely good, despite his whiteness.

Each of the cats now wears a collar and Abhorsen bell, but because Saraneth has been broken, Sabriel rings the bell called Ranna, that brings sleep. Their tiny bells take shape as Rannas, and both cats fall asleep. Again Nix's detail is ambiguous: are these two creatures now Sabriel's co-operative helpers, or will Ranna keep them asleep and so negate any willingness to help?s

The two cats vomit up the rings that Sabriel will need to control their energy forms, as an ordinary cat would vomit up a hairball. Like so much else in Sabriel, the significance of the cats' behaviour is not clear. Vomiting a ring is perhaps a forced yielding to the Abhorsen's magic power, but this reading brings Charter magic uncomfortably close to the nauseating influence of Kerrigor's misuse of power when he defiles the Stones. Mogget seems to offer the ring to Sabriel voluntarily on the first occasion, though his behaviour towards her, once 
freed, suggests that he murderously resents his confinement. Alternatively, vomiting the ring can be read as a helper's act, preparing for Sabriel's need to control the creature once it has taken on its energy form-but then, why would a helpful Mogget attack her? It can hardly be the case, either, that Kerrigor instantly transforms to a willing helper as soon as he becomes a black cat; yet he too vomits up a ring for Sabriel. This swirl of conflicting evidence cannot be reduced to the kind of black and white conclusion that the black cat, Kerrigor, and the white cat, Mogget, seem to promise.

The book's human characters in the world of the living can easily be differentiated into figures of good and evil, with no transition between these moral states, no good characters falling to temptation and no evil characters finding redemption. In death, however, black and white binary oppositions are not quite so easy to apply. Among the living, for example, Kerrigor is indubitably evil, but there is a strange scene at the beginning of the novel, in the river of death, where he is temporarily mistaken for one of the virtuous dead. Sabriel has just been born, her mother is dead and the baby also seems dead. Her father insists that she is still alive and goes into the river to retrieve her spirit, which has been picked up by Kerrigor. Though he has burning marshlights for eyes and emits the 'fetid stench of carrion' (p.4), the baby 'squirmed towards the creature, seeking a mother's breast... her little fists reached out to gather up the shadow-stuff of Kerrigor like the folds of a robe'(pp.4-5). The baby mistakes the monstrous foe of all Abhorsens for her dead mother. Sabriel's father is quick to rescue his daughter from both the river of death and Kerrigor, so that she is born a second time into life by way of her father overcoming a monstrous mother figure.

Perceiving an inhabitant of death's river as a mother figure is not merely a baby's misapprehension in this novel. When Sabriel's father sends a messenger up the river of death to give her his sword and bells, now that he is trapped, the dead creature comes trailing an 'umbilical' (p.15) thread back to the father. This image of a black umbilical cord puts Sabriel's father in the role of dead mother, sending a creature up and out of the river of death in a birth which ends-and must end, given the creature's nature-in a return to death. Later, when Sabriel rescues the prince, a similar umbilical cord connects him to some adept far down the river, but Sabriel births him and herself successfully,

using all her will to force them through the wards on the sinkhole. For an instant, it seemed that they would be repulsed, but then. like a pin pushing through a rubber band, they were through. (p. 142)

All of these images of umbilical cords and pushing render the river of death a monstrous birth canal whose current flows the wrong way, threatening to maintain connection via water and cord, to sweep the struggling spirit back down its waters, rather than helping the birth process out into the living world. Kerrigor, holding baby Sabriel, incarnates this monstrous death-mother seeking to reclaim the baby and reabsorb it into her watery womb.

The river as death-mother's wrong-way birth canal is a highly uncanny setting. As Freud comments of the female genital organs:

This unheimlich place, however, is the entrance to the former Heim (home) of all human beings, to the place where each one of us lived once upon a time and in the beginning. (1956, p.245)

In Freudian terms, every effort of Nix's dead to re-enter the world of the living can be interpreted as a repetition of Sabriel's first experience of death-seeming birth out of a dead womb. The book's repeated scenario of a dead creature effortfully wading out of the river, and Sabriel's duty to send them back in, would then read as an endlessly repeated return of the repressed, in Sabriel's case the terror and anguish of being born near-dead from a dead mother.

What returns from death in bodily form, however. is always male in this novel. Sabriel's dead mother returns as a benevolent spirit counsellor but her dead father returns in temporarily living flesh to rescue her and the world. Sabriel's antagonists are male. She is expected to take up her dead father's Abhorsen role; similarly, in Lirael, Lirael takes up her dead father's role as Abhorsen rather than her mother's Clayr talents and functions, and the king's daughter is preparing to rule when her father 
dies. This pattern of daughters assuming the father's functions is not matched in either novel by the son's taking on the mother's functions. It is daughters, only, who seem destined both to live out the dead father's life again and to combat older dead male antagonists. These two scenarios coincide in Sabriel at the point where Sabriel faces her great male enemy in the reservoir, and lacks the power to force him back to death. She brings her dead father back to life and he uses his brief span of life to ring the bell that pulls all its hearers into death. The act that saves Sabriel and the world, puts his daughter in danger of joining her father in final death. Thus the father, acting for good, re-establishing the boundary between the living and the dead, simultaneously acts like Sabriel's male enemies to put her life at great risk. In this respect the return of the repressed in Sabriel can be interpreted as the uncanny return of the father, the daughter's muchloved protector in the world of the living, yet at least temporarily indistinguishable from her demonic enemies. Sabriel cannot find an identity of her own in the novel: she repeatedly penetrates the symbolic birth-canal, operating as her father's replacement, and the return of the repressed in male form threatens to leave her stuck, as a quest warrior who has failed to survive the masculine, penetrating mode of experiencing the feminine waters of death.

Some final physical boundary is established for the good father and mother, even though they can still return in spirit form. The good dead in Sabriel find final safety in moving so far down the river that they cannot be reanimated. Their bodies are completely destroyed while they become bodiless spirits of light who bless and counsel Sabriel. This split between body and spirit is a familiar Christian dichotomy, and takes up the novel's references to the cross and the resurrection of the dead. To achieve Sabriel's version of heaven, one must become disembodied and so escape the prospect of return up the terrible mother's birth canal.

This birth canal is traversed with huge effort by the wielders of magic, to enable births and resurrections from the dead, while the current tugs the other way, into death. Sabriel herself dies at the end of the novel and is turned back by the blessed spirits, told that she cannot die until the next Abhorsen is born. Someone has to be the Abhorsen, able to keep stopping the 'wrong-way flow' of the dead upstream, and Sabriel must fulfil this role by herself travelling upstream and becoming reborn-a 'right-way' flow with the help of the blessed dead. Freud says of the story-teller's prose:

he is able to guide the current of our emotions, to dam it up in one direction and make it flow in another, and he often obtains a great variety of effects from the same material. (1956, p.251)

Such is the uncanny power of Garth Nix's Sabriel.

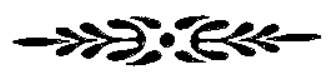

\section{END NOTES}

1. I put 'fantasy', 'marvellous' and 'uncanny' in inverted commas when I am using them in Todorov's sense. Elsewhere in my paper, fantasy means fiction that depicts a world different from ordinary waking human reality and the uncanny is used in Freud's psychoanalytic sense.

2. The fourth stretch of water has no peculiar dangers, and Nix gives no details as to the remaining sections.

3. With a pun on 'floe' and 'flow'.

4. Nix's sequel, Lirael, offers a fuller account of Mogget's origins and nature.

5. This question is partially answered in Lirael where Kerrigor is held captive in sleep and Mogget's ability to stay awake as a helper is very limited

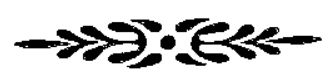




\section{REFERENCES}

Freud, Sigmund (1956) 'The Uncanny', Complete Psychological Works of Sigmund Freud edited by J. Strachey, vol. 4. London, Hogarth Press.

Hourihan, Margery (1997) Deconstructing the Hero: Literary Theory and Children's Literature. London, Routledge.

Nix, Garth (2001) Lirael. Sydney, Allen \& Unwin.

Nix, Garth (1995) Sabriel. Sydney, HarperCollins.

Todorov, Tzvetan (1975) The Fantastic: A Structural Approach to a Literary Genre trans. R. Howard. Ithaca, Cornell University Press.

http:/www.sf.org.au/aurealis/aa1995.html

\section{BIOGRAPHICAL NOTE}

Alice Mills is Associate Professor of literature and children's literature at the University of Ballarat. She has edited anthologies of children's literature for Random House and two collections of scholarly essays, Seriously Weird and (with Jeremy Smith) Utter Silence. She will be talking on Pollyanna at the AVSA conference in Adelaide.

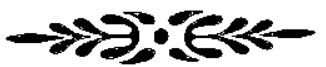

